\title{
Mulemba
}

Revista Angolana de Ciências Sociais

\section{Partilha do poder no Enclave Angolano de Cabinda: Modelo e processo}

Power-sharing in the angolan enclave of Cabinda: Model and process

\section{Miguel Domingos Bembe}

\author{
(2) OpenEdition \\ Journals \\ Edição electrónica \\ URL: http://journals.openedition.org/mulemba/416 \\ DOI: $10.4000 /$ mulemba.416 \\ ISSN: 2520-0305 \\ Editora \\ Edições Pedago \\ Edição impressa \\ Data de publição: 1 novembro 2014 \\ Paginação: 143-172 \\ ISSN: 2182-6471 \\ Refêrencia eletrónica \\ Miguel Domingos Bembe, «Partilha do poder no Enclave Angolano de Cabinda: Modelo e processo», \\ Mulemba [Online], 4 (8) | 2014, posto online no dia 28 novembro 2016, consultado o 26 janeiro 2021. \\ URL: http://journals.openedition.org/mulemba/416 ; DOI: https://doi.org/10.4000/mulemba.416
}

Este documento foi criado de forma automática no dia 26 janeiro 2021.

Tous droits réservés 


\title{
Partilha do poder no Enclave Angolano de Cabinda: Modelo e processo
}

Power-sharing in the angolan enclave of Cabinda: Model and process

\author{
Miguel Domingos Bembe
}

\section{NOTA DO EDITOR}

Artigo solicitado ao Autor

Recepção do manuscrito: 05/11/2014

Conclusão da revisão: 10/12/2014

Aceite para publicação: 30/12/2014

\section{NOTA DO AUTOR}

O presente artigo, escrito entre 27 de Setembro e 05 de Novembro e actualizado em 02 de Dezembro de 2014, resulta da Tese de Doutoramento em Ciências Sociais, na especialidade de Ciência Política, originalmente realizada e entregue no dia 02 de Outubro de 2013, sob o mesmo título, com um total de 325 páginas. A tese foi defendida em 13 de Maio de 2014, na Aula Magna Professor Doutor Adriano Moreira, do Instituto Superior de Ciências Sociais e Políticas (ISCSP) da Universidade de Lisboa (UL), tendo sido publicada em livro e efectuado o seu lançamento em 31 de Outubro de 2014, na Sala Monsanto do mesmo Instituto, em Lisboa, Portugal, com o título Mecanismos de partilha do poder e acomodação das elites. Modelo e processo para o Enclave de Cabinda (Lisboa, ISCSP, 2014, 368p.). Ele foi elaborado por convite do Director e Editor desta revista, em 25 de Setembro de 2014, para os quais expressamos a nossa mais sincera gratidão. Gostaríamos de sublinhar que as sugestões e críticas do Professor Virgílio Coelho 
contribuíram, de forma decisiva, no processo de revisão e na melhoria da qualidade do texto final aprovado.

«Já nos encontrámos várias vezes com a observação de que a obra dos governos é tanto mais eficaz quanto sabe valer-se dos resíduos existentes e tanto menos quanto mais os ignora, $\mathrm{e}$ que é geralmente ineficaz e vã quando aspira a mudá-los violentamente; e na realidade, quase todos os raciocínios sobre o porquê do triunfo ou fracasso de certos actos de governo reduzem-se a este princípio» (Vilfredo Pareto apud BESSA 1995:

\section{Introdução: justificação do tema}

1 A tese de doutoramento, da qual resultou o presente artigo, toma por base os resultados da dissertação subordinada ao título «A questão de Cabinda. Uma análise socio-política» (501p.), apresentada, em 31 de Março de 2009, em sede de Mestrado pré-Bolonha, em Ciências Sociais, na especialidade de Estratégia, no Instituto Superior de Ciências Sociais e Políticas (ISCSP) da então Universidade Técnica de Lisboa (UTL). ${ }^{1}$ A dissertação, editada e publicada em livro, em Angola em 2013 e lançado em 20 de Agosto do mesmo ano, em Luanda e em 30 de Agosto de 2014, em Cabinda, com o título A questão de Cabinda. Uma visão estratégica. Evolução da situação e cenários de futuro (620p.), apresentou a primeira crítica profunda, sistemática e rigorosa ao modelo de solução política adoptado para a Província Enclave de Cabinda.

2 A partir de um levantamento cuidado, foi desvendado o estado já avançado em que se encontra a estratégia nacional quanto à Província de Cabinda e o grau de realismo que a maioria dos movimentos independentistas a pouco e pouco vai fazendo seu. Não obstante o esforço desenvolvido neste estudo, ainda ficava quase tudo por fazer e dizer.

o Memorando de entendimento para a paz e reconciliação para a Província de Cabinda, assinado no dia 01 de Agosto de 2006, foi apresentado não como um simples compromisso de paz e reconciliação nacional, mas também como promessa de desenvolvimento socioeconómico e cultural e de crescente influência política para os Cabindeses.

4 Com a assinatura deste Acordo de Paz sobre Cabinda, o Governo da República de Angola e o Fórum Cabindês para o Diálogo (FCD), uniram-se em defesa do conjunto, submeteram-se aos interesses superiores do Estado e deram uma contribuição de inestimável valor para todos aqueles que, a nível interno do país e no plano externo continuam a acreditar no futuro da soberania de Angola.

5 Todavia, e embora o valor político-jurídico e até histórico do Estatuto Especial de Cabinda associado ao Memorando de entendimento, o modelo adoptado, bem como a ausência de planificação para a sua implementação parece não impulsionar qualquer mudança essencial no sistema político-ideológico do Estado e na estrutura e funcionamento do poder vigente no Enclave angolano.

6 Mas também, a crescente tendência para a gestão centralizada da questão de Cabinda, torna frágil as decisões que são tomadas e as acções promovidas para atenuar as causas 
da pobreza e da fome e os problemas e vícios do subdesenvolvimento multidimensional numa das regiões mais ricas em recursos naturais de Angola. A forte dependência político-institucional do Governo Provincial de Cabinda face ao Governo Central, tende a fragilizar a participação dos Cabindas nos processos de planeamento, tomada de decisão e gestão do Enclave.

Estas decisões são frequentemente tomadas sem beneficiarem de um processo efectivo, harmonioso e objectivo de preparação, teoricamente bem sustentado e que se desenvolva com maior rigor metodológico. Todas situações acima elencadas revelam definitivamente as profundas fragilidades nos mecanismos políticos, estruturais e operacionais de Cabinda e a sua continuação poderá, eventualmente, constituir-se, a médio e longo prazo, num potencial factor de instabilidade e reforçar a emergência de sinais de anomia política generalizada.

Depois disso não foram desenvolvidos esforços complementares para construir o consenso entre os requisitos decisórios e o instrumento formal instituído em Agosto de 2006, para a satisfação dessas exigências centrais.

Para além disso, a Constituição da República Angolana (CRA), ${ }^{2}$ promulgada a 05 de Fevereiro de 2010, reafirma, consagra e reconhece o carácter unitário do Estado, a democracia pluralista e representativa, as instituições de poder tradicional local, constituídas segundo o direito consuetudinário e a organização autónoma do poder autárquico local democraticamente legitimado. Mas, ao impedir qualquer possibilidade futura de viabilização de estruturas de auto-governo provincial e/ou eventualmente regional, parece constituir, mais de uma vez, uma «omissão» (uma omissão-lacuna jurídica, decerto politicamente intencional) sobre um dos assuntos paradigmáticos no conjunto angolano. ${ }^{3}$ Nestas circunstâncias, subsistem em Cabinda tensões latentes que obrigam a uma atenção constante, a acções faseadas baseadas nos princípios de bom senso e tolerância, que não escamoteiem as realidades diversas subjacentes e queiram adaptar as estruturas às pessoas e ao povo e não o inverso.

\section{Objectivos da pesquisa}

Ciente deste problema, a partir de estudo e criteriosa análise de um vasto conjunto de fontes abertas e informadores qualificados, aliados à imaginação criativa e ao bom senso, pretendeu-se realizar esta investigação de natureza qualitativa, na tentativa, sempre incompleta, de contribuir para um eventual aperfeiçoamento do modelo de resolução do conflito interno angolano, em Cabinda, instituído pelos regulamentos já acima referenciados. ${ }^{4}$

11 Para o efeito, conduziu-se a investigação no sentido de alcançar os seguintes nove (9) objectivos:

12 a) Identificar as causas e as motivações que estão na base da disputa política e social dos cabindeses;

b) Caracterizar as condicionantes geopolíticas e geoeconómicas de Cabinda;

c) Identificar e definir os contornos da sede do poder estratégico de Angola e demonstrar em que medida esta determina e condiciona o processo de desenvolvimento social, político, económico e cultural na província enclave de Cabinda; 
15 d) Analisar a estratégia da resistência de Cabinda para ultrapassar o isolamento operacional, político e diplomático, sobretudo entre 1997 e 2004;

e) Analisar a estrutura e o conteúdo do EEC de Agosto de 2006, como resposta do Governo às reivindicações políticas dos cabindeses, num exercício de identificar as possíveis deficiências nele existentes e de explorar as eventualidades ou possibilidades do seu aperfeiçoamento;

f) Adquirir um entendimento profundo sobre os aspectos teóricos que caracterizam as estratégias de contenção e gestão das diferenças, bem como as formas e componentes de partilha do poder e acomodação das elites, em especial, o federalismo, o consociativismo e o regionalismo;

18 g) Analisar a aplicabilidade do ajustamento do estatuto político da Província de Cabinda, numa lógica de gradualismo autonómico e de concertação, sem perder de vista a sua necessária contextualização à luz da realidade angolana;

h) Conceber um modelo original de partilha do poder no Enclave Angolano de Cabinda, que contribua para conferir um acréscimo de sustentação teórica e de rigor metodológico ao processo instituído pelo EEC;

i) Elaborar um estudo válido, razoável e simples, que não seja politicamente amorfo.

\section{Metodologia de investigação}

21 Como sublinhamos atrás, a presente investigação toma por base os resultados da dissertação de Mestrado. Neste contexto, apesar da facilidade, a escolha do tema ou pergunta de partida foi uma tarefa que exigiu uma cuidada reflexão, de forma a revelar exactamente com clareza, precisão, concisão, realismo e pertinência, o que se procura saber.

22 Como corolário dessa reflexão, resultou como pergunta de partida: «Que forma de partilha de poder poderá contribuir para conferir maior sustentação teórica e rigor metodológico ao processo instituído pelo EEC?» Esta questão foi o fio condutor da pesquisa e serviu para dar indicações sobre as leituras, as entrevistas e os métodos complementares exploratórios a utilizar para obter informação de qualidade sobre o tema. Assim, o tema foi aperfeiçoado em resultado da interacção entre as três primeiras etapas do método de investigação - pergunta de partida, exploração e problemática -, seguidas da construção do modelo, da permanente observação participante, da análise da informação e das conclusões.

Com as leituras exploratórias, procurou-se garantir a qualidade da problematização, ao mesmo tempo que permitiam tomar contacto com trabalhos que se debruçaram sobre objectos compatíveis. Reputou-se de grande significado metodológico a análise da documentação emitida por intervenientes no processo de decisão política e estratégica, e de alguns documentos que testemunham a actividade do poder político angolano, na definição de uma solução para o conflito em Cabinda. Foram também relevantes as leituras efectuadas noutras obras, algumas das quais com várias dezenas ou até centenas de anos.

Recorreu-se, maioritariamente, a trabalhos e artigos muito recentes e, na medida em que se trata de um assunto académico sobre o qual escasseiam obras específicas, optouse pela consulta de obras gerais e, sobretudo, de apoio teórico e metodológico, 
complementadas pelos ensaios publicados em revistas técnicas e pelo estudo de obras oficiais e oficiosas.

Foram feitos bastantes recursos às obras produzidas no ISCSP, porque elas sintetizam o saber da nossa Escola. Recorreu-se também a trabalhos próprios, uma vez que, tal como deixámos dito, a génese do modelo e processo de partilha do poder em Cabinda está na dissertação de Mestrado e noutros ensaios elaborados ao longo dos anos.

Todavia, e tal como é evidenciado pela bibliografia, muito do que é dito constitui propriedade intelectual de outros investigadores. E, considerando-se actualmente aquela dissertação de Mestrado como insuficiente, pretendeu-se elaborar esta tese para a aprofundar, no contexto da estratégia política para uma convivência mais saudável entre Cabinda e Luanda, tentando introduzir melhorias e focalizar o seu objecto num âmbito mais restrito e sobretudo inovador. Despendeu-se bastante energia na adaptação e na transposição do processo desenvolvido no modelo de solução de 2006, para o contexto da estratégia da regulação, contenção e gestão das diferenças num Estado democrático e de direito.

Ao longo da pesquisa, foi possível identificar o seguinte problema ou questão central: «Como conceber um modelo de partilha do poder em Cabinda, fundamentado nos conceitos operacionais das estratégias e modelos paradigmáticos contemporâneos para a regulação, contenção e gestão de conflitos político-identitários, que contribuam para conferir um acréscimo de sustentação teórica e de rigor metodológico ao processo instituído pelo EEC?» Este problema, ao qual a tese procurou responder, foi identificado a partir da comparação de diversas abordagens reveladas pelas leituras, pelas entrevistas e pelos métodos complementares, de forma a evidenciar aquela que se considera como a mais adequada para a investigação, caracterizada por quatro questões derivadas da questão central, que traduzem a problemática:

28 a) Que conceitos operacionais das estratégias de regulação, contenção e gestão de conflitos político-identitários são essenciais ao processo de partilha do poder em Cabinda no âmbito de Estado unitário angolano?

29 b) Qual a estrutura e quais as deficiências e possibilidades de aperfeiçoamento do modelo de resolução do conflito adoptado em Cabinda, face ao modelo associado de partilha do poder?

30 c) Que contributos oferecem os procedimentos inerentes às regras básicas e às técnicas recorridas pelos Estados para a regulação e gestão de conflitos, para estruturar o processo de partilha do poder em Cabinda?

31 d) Como é que a partir dos conceitos operacionais e dos procedimentos identificados, se pode conceber um novo modelo de partilha do poder em Cabinda, tirando partido da imaginação criativa e de alguns casos paradigmáticos contemporâneos, que contribua para conferir maior apoio teórico e rigor metodológico ao processo instituído em Cabinda?

32 Logo à partida, fez-se uma avaliação no sentido de ver se o problema podia ser resolvido pelo processo de pesquisa científica e se era suficientemente relevante para justificar a realização da investigação. Neste contexto, houve o cuidado de evitar que o entusiasmo ou os requisitos do vínculo efectivo e de vários anos a acompanhar esta questão levassem a optar ou a empreender um trabalho que, embora útil, fosse intelectualmente vulgar. 

para a sua adequação aos interesses pessoais, mas também para que respondesse à
preocupação muito marcante de se apresentar alguma novidade à comunidade
científica. e Pfaltzgraff Robert, que apostam em quatro abordagens básicas: o real (ou o ser), conhecido através do método da descrição; o possivel (ou o que pode ser), conhecido através do método da especulação; o provável (ou o que virá a ser), conhecido através do método da reflexão; e o desejável (ou o dever ser), conhecido através da reflexão normativa, valorativa ou ética (WRIGHT 1955: 26; DOUGHERTY e PFALTZGRAFF 2003: 64).

\section{Estrutura e síntese do conteúdo da tese}

Nesta perspectiva, a pesquisa realizada possui uma parte teórico-conceptual e outra de desenvolvimento. A primeira procura identificar, entender e explicar os motivos e as causas de convivência menos saudável entre Luanda e Cabinda, o conhecimento da sociedade de Cabinda e as possíveis redes de poder nela existentes. Analisa igualmente o sistema político angolano e a sua influência sobre Cabinda e as estratégias seguidas para uma mais conveniente integração da província enclave na República de Angola. A segunda parte examina e sistematiza os conceitos e os procedimentos recorridos pelos Estados nos cenários contemporâneos para a prevenção e resolução de conflitos político-identitários internos nas suas aplicações práticas.

Estruturou-se a investigação desta forma porque, num mundo cada vez mais competitivo, complexo e incerto, são necessários conceitos e procedimentos logicamente articulados em modelos que iluminem os aspectos fundamentais daquele enredo e reduzam a incerteza, para que o Estado enfrente com sucesso os desafios políticos e estratégicos e prossiga por caminhos que conduzam aos objectivos nacionais que elegeu.

Porém, a abordagem ao tema foi focalizada apenas nos assuntos que possuem uma utilidade directa para o processo político relativo à Cabinda. Esta decisão baseou-se na convicção de que, num trabalho académico, é impossível abarcar com profundidade e rigor tudo aquilo que diz respeito ao seu objecto.

Assim, o trabalho desenvolvido não pretende apresentar receitas para a resolução do conflito político-identitário no enclave de Cabinda através dos modelos de partilha do poder, e o seu conteúdo não possui o formato clássico de alguns estudos políticos, onde as matérias estão ordenadas como se fosse possível proceder à formulação de uma resposta política, independentemente do contexto da sua aplicabilidade.

o primeiro capítulo começa por operacionalizar o conceito do poder como objecto central e primacial da Ciência Política. Esta noção torna-se necessária para o estudo dos processos, dos actores, das dinâmicas e das tendências do desenvolvimento político de Cabinda, tendo por referência conceptual, o eixo do estudo do fenómeno político, como acontecimento implicado na luta pela aquisição, manutenção, exercício, controlo e subversão do poder na sociedade. Em seguida, justifica o tema explicando a necessidade e a motivação para a realização da investigação. Prossegue com a caracterização do contexto de desenvolvimento, ou, em outras palavras, o estabelecimento do estado da 
arte da pesquisa sobre Cabinda. Depois, define os objectivos a alcançar e indica a metodologia utilizada na investigação. Termina com a delimitação do processo de desenvolvimento do trabalho, explicando a sua estrutura e conteúdo.

O segundo capítulo sistematiza e identifica as causas e motivações que estão na base da contenda político-identitária e social em Cabinda. Analisa os compromissos de Simulambuco e a Lei fundamental portuguesa, evidenciando a evolução do estatuto do território de Cabinda, desde a administração colonial até aos nossos dias. Confronta os fundamentos de separatismo e da manutenção do Enclave na República de Angola. Prossegue com os futuros desejáveis e aceitáveis geralmente apresentados para Cabinda, incluindo a postura da diplomacia portuguesa e da comunidade internacional, que não vai para além do primado de angolanidade. Termina com a síntese conclusiva sobre as matérias abordadas no respectivo capítulo.

o terceiro capítulo apresenta as condicionantes geopolíticas e geoeconómicas de Cabinda. Analisa a evolução e as perspectivas gerais do sector económico do Enclave, incluindo os sectores de actividade no âmbito de comércio e serviços, transportes e comunicações, agricultura e pescas e estrutura profissional. Identifica o valor estratégico de Cabinda nos planos interno e externo. Finaliza com a síntese conclusiva, evidenciando que apesar da importância da província de Cabinda, em termos económicos e da intenção da liderança angolana para o desenvolvimento socioeconómico da região e atenuar os sentimentos de dissociação, as populações de Cabinda continuam muito pobres e em condições de vida abaixo dos padrões de Luanda, Benguela e Lubango, resultante das políticas e das estratégias adoptadas pelo Governo central sedeado em Luanda.

O quarto capítulo começa por analisar a evolução do sistema político angolano, isto é, a organização do Poder do Estado desde 1975 e a sua influência na organização e funcionamento do Governo da Província de Cabinda. Em seguida, identifica a estrutura e o papel das autoridades tradicionais na sociedade cabindesa, outras possíveis redes de poder nela existentes, e analisa alguns aspectos relacionados com a sociologia política, a cultura política e a comunicação política no Enclave angolano. Aborda de forma sistemática a evolução da resistência política e militar de Cabinda e, termina com uma síntese conclusiva, enfatizando que não obstante um maior acesso ao funcionamento formal do poder político em Angola, continua a haver grandes obstáculos a um conhecimento aprofundado dos mecanismos, dos processos e da dinâmica e dos actores operacionais do poder. ${ }^{5}$ Refere-se à dificuldade para conseguir identificar os elementos essenciais e estruturantes da sede do Poder estratégico de Angola, ou seja, aquele núcleo formal (ou formal não visível) e informal responsável pelos aspectos fundamentais de mecanismo e processo de decisão do Estado ou das organizações. É um exercício de difícil concretização devido ao centralismo e secretismo que envolve todo o sistema de poder, onde, no caso angolano, o Presidente da República possui, em simultâneo, a autoridade máxima de influência dentro das decisões do Estado e do Partido. Com efeito e como estabelece a Constituição (CRA, art.o 108 e seguintes), o Presidente da República exerce o poder executivo, auxiliado por um Vice-Presidente, Ministros de Estado e Ministros. Por sua vez, os Ministros de Estado e os Ministros são auxiliados por Secretários de Estado e/ou Vice-Ministros, se os houver. Nessa mesma qualidade, o Presidente da República dirige a administração directa do Estado, tem o poder de superintendência sobre a administração indirecta do Estado e o poder de tutela sobre a administração autónoma. Esta função implica uma grande intervenção do 
Presidente da República na gestão corrente dos assuntos de Estado, directamente, através dos seus órgãos auxiliares integrados no nível central pelos Departamentos Ministeriais e no nível local pelos serviços territoriais desconcentrados, representados pelos Governadores Provinciais. A intervenção indirecta do Presidente da República faz-se através dos institutos públicos, agências reguladoras e empresas públicas; e, de forma autónoma, através do Poder local autárquico e associações públicas, bem como por entidades administrativas independentes. No caso de Cabinda, a forte dependência político-institucional do Governo provincial face ao Executivo Central revela profundas fragilidades nos mecanismos e processos estruturais, operacionais e de gestão política do Partido/Estado. O «fatalismo» do subdesenvolvimento multidimensional da região, tende a ser descrito como o resultado da excessiva intervenção e controlo do Estado Central.

O quinto capítulo analisa e sistematiza a estratégia da resistência de Cabinda na viragem da conjuntura internacional (2001), regional (1997), interna (2002) para ultrapassar o isolamento operacional, político e diplomático (1997-2004). Trata-se da guerra global contra o terrorismo (Setembro de 2001), das alterações ocorridas no Congo-Kinshasa e Congo-Brazzaville (Maio e Junho de 1997), onde foram instituídos regimes pró-angolanos, mudanças reforçadas com a derrota da UNITA-militar (22 de Fevereiro de 2002) e a sua integração na vida política civil (desde 04 de Abril do mesmo ano). No discurso oficial do regime angolano, a FLEC - Frente de Libertação do Enclave de Cabinda e a UNITA - União Nacional para a Independência Total de Angola, no caso interno, passaram de movimentos nacionalistas e/ou de oposição a "grupos terroristas». Este capítulo prossegue com a estratégia política seguida pelo Governo do presidente José Eduardo dos Santos e pelos nacionalistas de Cabinda agrupados no Fórum Cabindês para o Diálogo(FCD), ${ }^{6}$ na tentativa de mudar a situação política, económica e social de Cabinda para uma mais conveniente integração do Enclave no espaço nacional angolano. Identifica os desafios políticos, económicos e sociais decorrentes da solução política adoptada em 1. de Agosto de 2006, através do Memorando de entendimento para a paz e reconciliação na Província de Cabinda que integra um Estatuto Especial para o Enclave. Termina com uma síntese conclusiva, apontando que embora o valor políticojurídico e até histórico indubitável do referido Estatuto, não existe qualquer evidência prática que permita provar alguma mudança essencial no sistema político em Angola, nomeadamente, na organização da estrutura e no funcionamento do poder vigente na província enclave de Cabinda.

o sexto capítulo expõe o instituto de partilha do poder e acomodação das elites. Examina e sistematiza os conceitos e alguns procedimentos recorridos pelos Estados nos cenários contemporâneos para a prevenção, gestão e resolução pacífica de conflitos político-identitários internos, tais como: o consociativismo, o regionalismo e o federalismo. Em seguida adopta e desenvolve um modelo integrado associado à autonomia regional considerado mais adequado para Cabinda no contexto nacional angolano. Prossegue com a apresentação do projecto de autonomia políticoadministrativo concebido para Cabinda, como uma indispensável etapa no longo prazo, numa perspectiva de acção contínua. Trata-se da tentativa de apresentar, não só, o modelo e o processo político prospectivo para Cabinda, isto é, do que poderá ser, mas também, a posição do que deverá ser, sem perder de vista a sua contextualização à luz da realidade nacional. Depois, tenta esclarecer a aplicabilidade gradual do modelo integrado proposto no âmbito do Estado unitário angolano. 
O sétimo e último capítulo reúne as principais conclusões e apresenta a ideia global da investigação que foi feita. Na prática, procura apenas situar o problema, uma vez que a investigação conduziu a um conjunto diversificado de sínteses conclusivas, já incluídas nos respectivos capítulos.

\section{Principais conclusões da tese}

O fio condutor desta investigação foi a pergunta de partida: «Que forma de partilha de poder poderá contribuir para conferir maior sustentação teórica e rigor metodológico ao processo instituído pelo EEC?».7 A sua versão final resultou, principalmente, da interacção com a fase de exploração, na qual foram realizadas as leituras e as entrevistas exploratórias, para a aquisição de informação de qualidade, sustentadas numa permanente observação participante.

Com efeito, a investigação começou por sistematizar e identificar os primórdios da questão de Cabinda e concluiu que os factores histórico-geográfico e cultural, ambições política e territorial e condições social e económica são os motivos fundamentais que estão na base do nacionalismo de dissociação independentista dos cabindeses.

Verificou-se que alguns arranjos internos operados no estatuto do agitado território de Cabinda, desde a administração portuguesa à actualidade, tenderam a desrespeitar o espírito do tratado de Simulambuco, entendido como instituidor de um protectorado, bem como a reconhecida identidade de «povo» de Cabinda, que o apontava para um eventual tratamento distinto.

Entre os anos 1975 e 2006, o Governo Angolano tendo conseguido conservar os movimentos nacionalistas de Cabinda politicamente controláveis (BEMBE 2013a: 331-332):

a) Retardou o processo de negociações, enquanto se manteve algum factor favorável aos nacionalistas, que poderia proporcionar «futuros indesejáveis», ${ }^{8}$ ou seja, que não serviam as finalidades últimas da política nacional traçada pelo Governo;

b) Reforçou e sustentou a fissiparidade nas organizações nacionalistas cabindesas e explorou com oportunidade as divergências dos seus líderes, ${ }^{9}$ para argumentar que «não há um interlocutor válido para negociar a paz em Cabinda»; ;0

c) Desviou as atenções dos dirigentes da resistência e da sociedade civil de Cabinda sobre assuntos que realmente importavam à sua luta, nomeadamente, a previsão das tendências e o estabelecimento de futuros possíveis (médio e longo prazo), através da interpretação dos ambientes externo e interno; e,

d) Consolidou os cenários já estabelecidos sobre os futuros "desejáveis e aceitáveis», ${ }^{11}$ considerados como melhores para Cabinda, nomeadamente a mais conveniente integração da província enclave no espaço nacional, reconhecendo a sua especificidade no contexto angolano.

Para isso, o Governo Central comprometeu-se a assegurar, em cooperação com o Governo da Província, o desenvolvimento administrativo, económico e social de Cabinda, considerando as suas potencialidades e a necessidade da superação das assimetrias decorrentes da especificidade geográfica. A solidariedade nacional vincula, ainda, o Estado a garantir as condições para ultrapassar as consequências da situação de 
Enclave e a sua melhor integração gradual no espaço nacional num quadro de interdependência económica e financeira. ${ }^{12}$

Todavia, e como dissemos atrás, a realidade observada no terreno tende a demonstrar o inverso. A falta de empenho do Estado-Partido aparelho do poder para atenuar os sentimentos independentistas em Cabinda, parece evidente com a persistência da convivência menos saudável entre Cabinda e Luanda que encontra um terreno fértil, nomeadamente:

a) no menor impacto social das estratégias e políticas adoptadas na região;

b) no sub-desenvolvimento político, económico e social do Enclave;

c) no consumado estado da pobreza e vulgarização de condições de vida da maioria dos cabindeses ${ }^{13}$ muito próximas da mera subsistência;

d) na degradação e insuficiência das infra-estruturas básicas, de meios técnicos, de recursos humanos qualificados na província;

e) na crescente dependência de Cabinda em relação à Luanda e aos dois Congos vizinhos.

61 As vastas reservas petrolíferas de Cabinda, mas sobretudo, o petróleo extraído no Enclave, que representa mais de $65 \%$ do valor total do petróleo explorado e produzido no território angolano, e que cobrem cerca de $2 / 3$ das receitas totais do Estado (Cf. 0 País [Luanda], 23 de Agosto de 2010; Lusa e SIC [Lisboa], 01 de Maio de 2013); o peso dos rendimentos deste recurso não reflecte nas duas problemáticas únicas: assegurar a melhoria de vida dos cabindeses e a sustentabilidade económica da província.

Deste modo, entre outros factores, o nacionalismo de dissociação exprime-se com vigor renovado, precisamente no momento em que os cabindeses se sentem excluídos nos processos de planeamento, tomada de decisão e gestão dos destinos da própria Província e, na ausência de reformas eficazes que promovam sistemas de participação e representação que consolidem e ampliem os mecanismos da sua integração no processo democrático angolano. Como princípio de afirmação da especificidade histórica, cultural, política e social de um povo, de modo geral, o nacionalismo tem tido um alcance libertador. Oprimidos, reprimidos ou eventualmente massacrados, «alguns povos não poderiam superar a sua vulnerabilidade existencial senão indo até ao extremo da lógica nacional a fim de edificar um Estado que finalmente lhes desse, por intermédio da soberania, a segurança colectiva à qual aspiravam com tanto vigor» (DIECKHOFF 2001: 16-17). ${ }^{14}$

A forte dependência político-institucional do Governo Provincial de Cabinda em relação ao Poder Central, bem como os altos índices da fome, da pobreza e do subdesenvolvimento social, económico e político na região enclave, são descritos como consequência da excessiva intervenção e/ou controlo do Estado Central. Assim, a cultura organizacional é uma das componentes básicas e decisivas na análise da problemática do desenvolvimento político no Enclave Angolano. Tal como se verifica em quase todo o continente africano, em Angola, os outros órgãos do poder estão ainda na fase do «simbolismo». ${ }^{15}$

Evidentemente, a administração local praticada em Cabinda é, ao nível macro-político, um instrumento fundamental para a sobrevivência do Executivo/Partido, enquanto que ao nível micro-político funciona como uma ferramenta de conversão das exigências paroquiais de grupos de interesse e do clientelismo da elite política. O modelo governativo promovido em Cabinda é muito fraco e vulnerabilizado pela robusta centralização política exercida pelo Partido/Estado e, a falta de acesso à decisão política 
conduz ao pagamento de favores e à corrupção, que se torna uma parte do processo e mina o respeito e a legitimidade que a administração local necessita.

Foi, ainda, possível verificar no terreno alvo de estudo, a problemática seguinte:

a) por um lado, hoje como no passado, Cabinda continua a desempenhar a sua função de sempre, isto é, centro da exploração, do comércio e das transacções relacionadas com exportações dos produtos lucrativos, e centro da maior importação dos produtos alimentares e géneros de primeira necessidade;

b) por outro lado, a dignidade normativa das «competências especiais de âmbito específico» que se pretendeu atribuir à província de Cabinda no âmbito do Estatuto Especial tendeu a ser manipulada pela mentalidade centrista e ideologia de exclusão que continua, infelizmente, a predominar entre nós.

À essa dignidade será sempre difícil fazer corresponder os planos de desenvolvimento socio-económico e político da própria província e os recursos necessários, nomeadamente humanos, económicos e financeiros, para tal efeito. Este afigura-se, um problema magno para os decisores políticos de Angola, considerando que a construção de um quadro da estratificação social actual cabindês deve obedecer ao cruzamento de três variáveis essenciais: estatuto económico, estatuto social e estatuto político.

Daí o fundamento da nossa abordagem, segundo a qual, qualquer aproximação ao estudo da sociedade de Cabinda parece implicar, necessariamente, a análise e caracterização das variáveis étnico-tribal, histórico-cultural, socio-política e económica da região. A percepção destas componentes é essencial no desenhar de um conjunto de possíveis soluções de carácter geral e específico, para os problemas e novos desafios detectados.

Face aos três modelos de partilha do poder apresentados, com destaque para o consociativismo, o regionalismo e o federalismo, foi adoptado e concebido um modelo de partilha do poder que melhor se adeque à Cabinda, tendo em conta a sua aplicabilidade no contexto angolano, bem como a capacidade de reduzir ao mínimo o aparecimento de novos problemas ou vulnerabilidades a nível do país. Trata-se do modelo integrado associado a uma autonomia política de base regional, tendo em consideração a sua necessária contextualização à luz da realidade nacional e as vantagens e inconvenientes que pode desenvolver.

Em síntese, o modelo proposto na tese visa materializar quatro (4) objectivos fundamentais, a saber:

a) Prosseguir com a prática da cooptação política variável das elites de Cabinda pelo Estado-Partido aparelho do poder;

b) Reconhecer o Estatuto especial de Cabinda na Constituição da República Angolana (CRA) e consagrar um governo regional cabindês com competências bem definidas (o que acarreta uma revisão pontual da CRA, bem como acertar porventura algum outro detalhe formal);

c) Alargar a desconcentração e a aproximação dos serviços públicos às populações; $\mathrm{e}$

d) Efectivar a descentralização política e administrativa na região Enclave Angolano.

Sendo um problema iminentemente político, a descentralização proposta consiste na devolução gradual de poderes de decisão pela administração central aos órgãos próprios da região administrativa de Cabinda, produzindo, consequentemente, uma redistribuição do poder político. 

diálogo e concertação permanente entre o Poder Central e as elites Cabindas responsáveis (oriundos da classe política, das igrejas, autoridades tradicionais, activistas cívicos, individualidades e intelectuais) parece-nos o método mais adequado para a sua concretização. cabindesas no âmbito do desenvolvimento do modelo proposto. Fica, assim, implícita, a necessidade de o Estado-Partido aparelho do poder evitar qualquer avanço accelerado com recurso a força e/ou a mecanismos unilaterais que não implicassem devidamente as principais elites de Cabinda. Nunca perder de vista que o Memorando de Entendimento de 2006, a base de qualquer processo multidimensional para a província de Cabinda, foi obtido no espírito de reencontro do Povo Angolano.

Para a concretização do modelo integrado proposto para Cabinda, foram apresentados, em pormenor, cinco (5) vectores fundamentais, a saber:

- 1. Vector: Conferir a Cabinda uma considerável autonomia de decisão política, competências específicas e uma organização particular, bem como um poder legislativo próprio. Por um lado, os factores geográficos, histórico-culturais e políticos (reconhecidos no Estatuto Especial), devem ser elementos diferenciadores da administração de Cabinda face às restantes províncias. Por outro lado, a consciência da distância nunca pode ser ignorada, e isso sempre que se aborda o instituto de autonomia para a Província Enclave de Cabinda.

81 - 2.ำ Vector: Definir competências, nos domínios administrativo, financeiro e técnico, tanto da autoridade do Estado como da do poder regional de Cabinda. A regionalização de Cabinda é uma questão essencialmente técnica, isto é, uma mera criação de áreas administrativas de acordo com critérios claramente definidos. A descentralização é um problema fundamentalmente político e jurídico. Se não se realizarem as condições, particularmente a da autonomia jurídica, financeira e técnica - a descentralização não terá verdadeiro conteúdo.

82 - 3.. Vector: Promover um modelo regional educacional em Cabinda flexível mas exigente e de formação de excelência, com mais direito a um lógico reconhecimento. Nenhuma autonomia política tem sustentabilidade sem um investimento prioritário na educação. A educação e a valorização da pessoa humana são a base fundamental para qualquer sucesso na política de desenvolvimento integral. Parece, entretanto, difícil compreender como uma administração se poderá adaptar ao seu meio ambiente social e cultural, com funcionários que não conhecem a realidade ou são hostis a esse ambiente.

- 4.․ Vector: Envolver e empenhar os Cabindas no processo de desenvolvimento da região enclave e de melhoria das suas condições de vida - sobretudo as elites do território. Do ponto de vista económico, a descentralização veicula indubitavelmente em si mesma uma vontade de ecodesenvolvimento. O plano do desenvolvimento económico para Cabinda, deverá atribuir também uma atenção especial à promoção $\mathrm{e}$ consolidação das instituições políticas, sem as quais, como a experiência o demonstra, qualquer tentativa no sentido do desenvolvimento sócio-económico estará bastante fragilizada. A principal dimensão do desenvolvimento político tem a ver com o processo pelo qual os indivíduos se tornam cada vez mais participativos e integrados na acção política (BEMBE, 2013a: 467; 2013b: 178; 2014: 134).

84 - 5. Vector: Promover uma colaboração entre o Poder Central e poder regional Cabindês, no âmbito da definição dos objectivos a atingir e na avaliação dos interesses a 
satisfazer. No processo de criação da região autónoma de Cabinda e de efectivação da descentralização política e administrativa, é imprescindível garantir um Estado forte, capaz de promover e assegurar a coesão nacional e de definir as grandes prioridades de desenvolvimento do País.

O processo de regionalização é assim uma indispensável etapa para Cabinda no longo prazo, numa perspectiva de acção contínua e gradual. Trata-se de definir um espaço geográfico dentro do qual se possa exercer, de forma autónoma e exclusiva, um conjunto de competências, ainda que mais ou menos tuteladas, em ordem ao desenvolvimento económico e social, em que terá em mente a eliminação das assimetrias e desequilíbrios regionais/provinciais, em ordem à correcção das desigualdades, à melhoria das condições de vida e à promoção da cultura das populações.

0 modelo que se propõe como resposta à pergunta de partida, foi concebido pela articulação lógica, com recurso à imaginação criativa dos conceitos operacionais das estratégias de prevenção e resolução de conflitos com os procedimentos proporcionados pelas regras básicas e pelas técnicas aplicadas no EEC, estabelecido nos termos do MEPRC, bem como nos conhecidos modelos paradigmáticos frequentemente recorridos pelos Estados nos cenários contemporâneos para solucionar conflitos internos, secessionistas, político-identitários ou socio-culturais.

Esta proposta que - inclui a sociedade civil de Cabinda, lato senso, como elemento indispensável do processo de desenvolvimento político do Enclave -, parece reforçar a unidade nacional, na medida em que o «Povo de Cabinda», passando a deter os meios de desenvolvimento integral a que tem direito, sentir-se-á, provavelmente, bem no seio de Angola, plenamente identificado com a Nação Angolana. Enfatiza-se este aspecto porque, o tema foi aperfeiçoado em resultado da interacção verificada entre as três primeiras etapas do método de investigação - pergunta de partida, exploração e problemática -, seguidas da construção do modelo, da observação, da análise da informação e das conclusões.

88 A abordagem adoptada afigura-se-nos essencial, pois, os Cabindeses tenderão a encontrar na autonomia política no seio da República de Angola, o seu caminho de emancipação. Essa autonomia política progressiva é um processo dialéctico constante que, se colonialmente impedido, poderá fazer regredir o esforço de coesão nacional, até agora conseguido manter, mas de impossível sustentação futura, caso sejam esfrangalhadas as propostas autonomistas de Cabinda, vindas das elites angolanas em geral, bem como cabindenses e cabindesas em particular.

Como sublinhámos atrás, não se trata de reformar o «Estado-nação» angolano (ainda em construção), nem tão pouco de o ver substituído no futuro pelo Estado democrático multinacional. ${ }^{16}$ Não se trata ainda de substituir o Estado no desempenho das suas clássicas tarefas para dar resposta às razões da sua existência. ${ }^{17}$

O que aqui está em causa é uma modalidade do princípio geral da participação política. Parece fundamental envolver e empenhar os Cabindeses - sobretudo as elites do território -, no processo de desenvolvimento integral da região e na melhoria das suas condições de vida. O Enclave, enquanto espaço de autonomia política, deve obedecer à lógica da democracia participativa local e não apenas à lógica da democracia representativa estatal. 
91 Todavia, se a desconcentração e a descentralização afiguram-se-nos fundamentais, igualmente parece necessário garantir o exercício de um Estado forte, capaz de promover e assegurar a coesão nacional e de definir as grandes prioridades de desenvolvimento do País (BEMBE 2012: 49-51). ${ }^{18}$

Pretende-se, à partida, esbater a histórica tentação separatista de Cabinda, com recurso aos conhecidos e reputados modelos de regulação, contenção e gestão de conflitos político-identitários internos, ajustáveis à realidade nacional. O novo modelo deve levar em consideração as especificidades do Enclave no conjunto angolano, reconhecidas na lei ordinária mais de uma vez referenciadas neste trabalho. ${ }^{19}$ Com efeito, a identidade enquanto conceito que aparece na articulação da psicologia e da sociologia, abarca duas dimensões essenciais: "as ideias de representação de si e de reivindicação da diferença» (FERNANDES 1992: 46).

93 Afigura-se-nos, entretanto, inconveniente avançar com esta importante e irresistível proposta durante o período da construção do Estado de direito e da consolidação das instituições democráticas em Angola, tendo em conta o passado de nacionalismo cabindês de dissociação.

Parece essencial e bastante aceitável explorar a eventualidade de atribuição à Cabinda, numa primeira fase (curto/médio prazos):

95 a) A combinação de poderes mais fortemente desconcentrados do que as restantes Províncias do país e restabelecer a autonomia da gestão pelo Governo provincial, dos dez por cento (10\%) das receitas fiscais petrolíferas da região destinadas à própria província (a curto prazo); e,

96 b) A autonomia municipal de tipo autárquico mais alargada, bem como poderes alargados nas áreas de cultura e exploração de recursos (a médio prazo), com base no seu Estatuto Especial (como elemento diferenciador da administração do Enclave face às outras províncias angolanas).

97 Convirá não esquecer que há sempre uma distância considerável entre a teoria e o seu emprego no mundo real, que deve ser respeitada e gerida com inteligência. É inegável que os resultados obtidos permitiram compreender com aceitável profundidade a teoria do processo de prevenção, gestão e resolução de conflitos de tipo secessionista, com base em conceitos e em procedimentos relevantes.

98 Finalmente, foi alcançado o objectivo de elaboração de um trabalho válido, sóbrio e simples, em consequência de uma investigação que contemplou a pesquisa da informação pertinente, a sua discussão e a apresentação de uma resposta concreta, que foi efectuada obedecendo a critérios de aceitabilidade, de objectividade, de generalidade, de rigor científico, de utilidade e de refutabilidade. ${ }^{20}$

99 Não se pretendeu elaborar uma investigação politicamente amorfa. Com esta peregrinação, quis-se adiantar nesta via do saber e, tanto quanto possível, fiel aos dados da realidade, pois esta, também ensina os homens a ser mais homens. Sobretudo num tempo em que - como avisara Alexandre Herculano, sem imaginar que enunciava uma tendência a longo prazo - «na maioria das sociedades actuais falta geralmente aos homens públicos o valor não só para ousar o bem, mas, até, para praticar fracamente o mal» (HERCULANO 1863: 10).

100 Se o separatismo, isto é, a constituição de um Estado independente plenamente soberano, é essencialmente o caso dos nacionalismos radicais, resta, no entanto, uma última interrogação: Poderão os movimentos nacionalistas moderados satisfazer-se com uma 
autodeterminação que não culminaria na independência? Em palavras mais simples, contentarse-ão os dirigentes Cabindeses com uma autonomia, mesmo que bastante ampla, no contexto nacional angolano?

101 Razão de sobra assiste Alain Dieckhoff quando afirma que «oficialmente os dirigentes flamengos e catalães nunca deixaram de proclamar que a auto-afirmação da sua região no seio de uma Europa cada vez mais federal é suficiente para a sua felicidade» (DIECKHOFF 2001: 129). Mas, na realidade, ao reivindicarem cada vez mais competências ou a implementação do confederalismo, eles insistem em avançar abertamente na via de uma independência. ${ }^{21}$ No entanto, esta perspectiva nada tem de inevitável. Ela será evitada se os Estados modernos demonstrarem uma capacidade real para repensar o seu funcionamento interno de forma a terem positivamente em consideração estas reivindicações a que devem fazer face.

Como afirma Henry Kissinger «uma política movida pelo critério do interesse nacional, não pode funcionar se não for minimamente adequada aos interesses daqueles que procura envolver, $e$ os que a executam não podem ser convincentes se não acreditarem no que estão a fazer» (KISSINGER 2003a: 794). Se esta foi ensaiada no Enclave Angolano de Cabinda, daí dificilmente resultará acatamento popular do processo e das decisões tomadas, o que redundaria em ferir o interesse nacional prosseguido (BEMBE 2014: 258).

A exclusão, a fome e a pobreza corroem e são impeditivas de uma coesão nacional sadia. Por isso se justifica, amplamente, o cuidado que deve merecer, ao poder político, a delicada problemática da coesão nacional. Se o poder mede-se pela capacidade decisional, reclamada, de forma muito sonante, pelos chamados sectores moderados de Cabinda, então, de agora em diante, é aconselhável que a província enclave de Cabinda tenha capacidade, por direito próprio e exclusivo, de decidir, sem se limitar a uma cooperação cooptativa com o Poder Central (BEMBE 2013b: 176; 2014: 258). É imperioso conjugar a representação e a participação, a economia e a política, a família e as instituições do Estado. Quando às pessoas e aos grupos forem devolvidas as suas responsabilidades, que o «Estado-providência» assumiu, ou apenas pretendeu assumir, poderá operar-se, com naturalidade, uma nova vida e uma nova forma de organização sociais, ou, simplesmente, o desenvolvimento social multidimensional e sustentado da comunidade e da região onde exerce a sua actividade (BEMBE 2012: 52). 
Figura 1 - Modelo e processo de partilha do poder no Enclave Angolano de Cabinda - Uma abordagem contínua e gradual (Longo prazo, a partir de 2014)

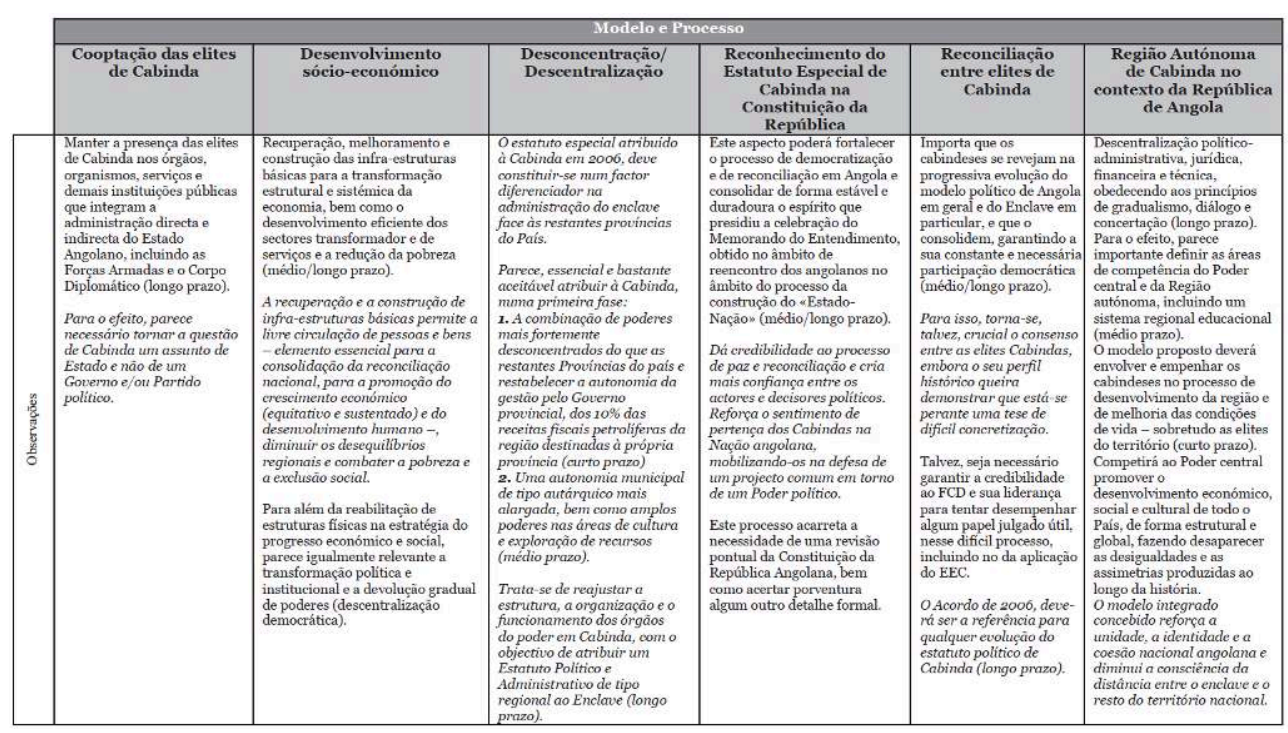

FONTE - Quadro elaborado pelo autor a partir do estudo e análise de um vasto conjunto de fontes abertas e de análises de informadores qualificados.

\section{BIBLIOGRAFIA}

BEMBE Miguel Domingos, 2012, «Poder local e democracia em Angola. Oportunidades e desafios», in Mulemba - Revista Angolana de Ciências Sociais (Luanda), vol. II, n. 3, Maio, pp. 35-57.

BEMBE Miguel Domingos, 2013a (1. a edição), A questão de Cabinda. Uma visão estratégica. Evolução da situação e cenários de futuro, vol. I. Prefácios de António de Sousa Lara e Armando Marques Guedes. Luanda, Edição do Autor; Edições de Angola.

BEMBE Miguel Domingos, 2013b, «Os vectores da construção da "Nação-angolana" e a função do Estado", in Mulemba - Revista Angolana de Ciências Sociais (Luanda), vol. III, n. ํ 6, Novembro, pp. 167-183.

BEMBE Miguel Domingos, 2014, Partilha do poder no Enclave Angolano de Cabinda. Modelo e processo. Tese de Doutoramento em Ciências Sociais, na especialidade de Ciência Política, orientada por António de Sousa Lara e coorientada por Armando Marques Guedes e defendida no Instituto Superior de Ciências Sociais e Políticas da Universidade de Lisboa, em 13 de Maio de 2014.

BESSA António Marques, 1993, Quem governa? Uma análise histórico-política do tema da elite. Lisboa, Instituto Superior de Ciências Sociais e Políticas, Universidade Técnica de Lisboa.

BESSA António Marques, 1995, A arte de governar: Ensaios sobre classe dirigente e fórmula política. Lisboa, Instituto Superior de Ciências Sociais e Políticas, Universidade Técnica de Lisboa.

BESSA António Marques, 2012 (2.e edição revista e ampliada), O olhar de Leviathan: Uma introdução à política externa dos Estados modernos. Lisboa, Universidade Autónoma de Lisboa. 
BINNINGSBO Helga Malmin, 2013, «Power-sharing, peace and democracy: Any obvious relationships?», in International Area Studies Review, n. 16, Março, pp. 89-112.

BRAGANÇA Dom Duarte de, 2001a, «Cabinda e Timor», Lisboa, Diário de Notícias, 25 de Março. $<$ http://www.angelfire.com/pq/unica/causa_dd_2001_cabinda_e_timor.htm>, acessado em 15 de Julho de 2013.

BRAGANÇA Dom Duarte de, 2001b, «Cabinda e Timor», in Revista Real (Lisboa), n.․ 47/48, AbrilSetembro, pp. 12-13.

CAUPERS João, 1994, Administração periférica do Estado. Estudo de Ciência da Administração. Lisboa, Editorial Notícias e Aequitas.

DAHL Robert A., 1989, Democracy and its critics. New Haven, Yale University Press.

DEUTSCH Karl, 1963, The nerves of Government: Models of political communication and control. New York, The Free Press.

DIAS Abel António Ponciano da Piedade, 1967, Alguns aspectos histórico-políticos e administrativos de Cabinda até 1910. Lisboa, Instituto Superior de Ciências Sociais e Políticas, Universidade Técnica de Lisboa.

DIECKHOFF Alain, 2001, A Nação em todos os seus Estados. As identidades nacionais em movimento. Lisboa, Instituto Jean Piaget.

DOUGHERTY James E. e PHALTZGRAFF Robert, 2003 (1. a edição), Relações Internacionais. As teorias em confronto. Lisboa, Gradiva.

EASTON David, 1953, The political system: An inquiry into the state of political science. New York, Alfred A. Knopf.

FEIJÓ Carlos, 2001 (1. edição), Problemas actuais de Direito Público Angolano. Contributos para a sua compreensão. Lisboa, Editorial Principia.

FERNANDES António Teixeira, 1992, «Poder Local e Democracia». Comunicação apresentada ao II Congresso Português de Sociologia, Lisboa, Fundação Calouste Gulbenkian, 5 a 7 de Fevereiro.

GUEDES Armando Marques et al., 2007, State and traditional law in Angola and Mozambique. Coimbra, Edições Almedina.

HERCULANO Alexandre, 1983 (Tomo I), História de Portugal. Lisboa, Bertrand.

KAJIBANGA Víctor, 2009, «Democracia e dimensão cultural de desenvolvimento: Uma reflexão sociológica sobre o caso africano», in Revista Angolana de Sociologia (Luanda), n. 3, pp. 65-72.

KISSINGER Henry, 2003a (1. edição), Anos de renovação. Lisboa, Gradiva.

KISSINGER Henry, 2003b (1.ํe edição), Precisará a América de uma política externa? Uma diplomacia para o século XXI. Lisboa, Gradiva.

LARA António de Sousa, 1987, A subversão do Estado. Lisboa, Instituto Superior de Ciências Sociais e Políticas, Universidade Técnica de Lisboa.

LARA António de Sousa, 2000, Colonização moderna e descolonização: Sumários para o estudo da sua história. Lisboa, Instituto Superior de Ciências Sociais e Políticas, Universidade Técnica de Lisboa.

LARA António de Sousa, 2002, Imperialismo, descolonização, subversão e dependência. Lisboa, Instituto Superior de Ciências Sociais e Políticas, Universidade Técnica de Lisboa.

LARA António de Sousa, 2007 (4. edição), Ciência política: Estudos da ordem e da subversão. Lisboa, Instituto Superior de Ciências Sociais e Políticas, Universidade Técnica de Lisboa. 
LESSARD-HEBERT Michelle; GOYETTE Gabriel e BOUTIN Gérald, 1994, Investigação qualitativa: fundamentos e práticas. Lisboa, Instituto Jean Piaget.

LIJPHART Arend, 1968, The politics of accommodation: Pluralism and democracy in the Netherlands. Berkeley, University of California Press.

LIJPHART Arend, 1977, Democracy in plural societies: A comparative exploration. New Haven e Londres, Yale University Press.

LIJPHART Arend, 1984, Democracies. Patterns of majoritarian and consensus government in twenty-one countries. New Haven e Londres, Yale University Press.

LIJPHART Arend, 1989, «The power-sharing approach», in J. Montville (ed.), Conflict and peacemaking in multiethnic societies. New York, The Free Press, pp. 93-106.

LIJPHART Arend e HOTTINGER Julian Thomas (coords.), 1977, «Dossier les démocraties consociatives: Changement et continuité dans la théorie consociative», in Revue Internationale de Politique Comparée, vol. 4, n. $^{\circ} 3$.

MALTEZ José Adelino, 1994, Sobre a Ciência Política. Lisboa, Instituto Superior de Ciências Sociais e Políticas, Universidade Técnica de Lisboa.

MALTEZ José Adelino, 2007, Metodologias da Ciência Política: o Estado à procura do político. Relatório das provas de agregação apresentado em 1996. Lisboa, Instituto Superior de Ciências Sociais e Políticas, Universidade Técnica de Lisboa.

MARTINS Manuel Meirinho, 2004, Participação política e democracia: O caso português (1976-2000). Tese de doutoramento em Ciências Sociais, na especialidade de Ciência Política. Lisboa, Instituto Superior de Ciências Sociais e Políticas, Universidade Técnica de Lisboa.

MARTINS Manuel Meirinho, 2010, Cidadania e participação política: Temas e perspectivas de análise. Lisboa, Instituto Superior de Ciências Sociais e Políticas, Universidade Técnica de Lisboa [«Manuais Pedagógicos»].

MILANDO João, 2013, Desenvolvimento e resiliência social em África: Dinâmicas rurais de Cabinda, Angola. Luanda, Mayamba Editora.

OTAYEK René, 2007, «A descentralização como modo de redefinição do poder autoritário? Algumas reflexões a partir de realidades africanas», in Revista Crítica de Ciências Sociais (Coimbra), n.o 77, Junho, pp. 131-150.

RIBEIRO António da Silva, 1998, Planeamento da acção estratégica aplicado ao Estado. Lisboa, Editorial Minerva.

RIBEIRO António da Silva, 2010, Política de defesa nacional e estratégia militar. Modelo de elaboração. Lisboa, Diário de Bordo.

ROMANA Heitor Barras, 1997, São Tomé e Príncipe. Elementos para uma análise antropológica das suas vulnerabilidades e potencialidades. Tese de Mestrado em Estudos Africanos. Lisboa, Instituto Superior de Ciências Sociais e Políticas, Universidade Técnica de Lisboa.

ROMANA Heitor Barras, 2005, República Popular da China. A sede do poder estratégico. Mecanismos do processo de decisão. Coimbra, Almedina.

WRIGHT Quincy, 1955, The study of International Relations. New York, Appleton-Century-Crofts. 


\section{NOTAS}

1. Hoje, Universidade de Lisboa (UL), a maior universidade de Portugal, que resulta da fusão das duas maiores, e mais antigas universidades de Lisboa, designadamente, a Universidade de Lisboa (UL), também conhecida por Universidade Clássica de Lisboa, criada em 22 de Março de 1911, com a Universidade Técnica de Lisboa (UTL), criada em 02 de Dezembro de 1930. A fusão foi aprovada pelo Decreto-Lei n.o 266-E/2012, de 31 de Dezembro, tendo sido concretizada com a tomada de posse do primeiro Reitor, António Cruz Serra, em 25 de Julho de 2013 [Nota do editor].

2. Composta por 8 títulos, 244 artigos e 3 anexos (relativos aos símbolos da República: Bandeira, insígnia e hino nacionais), a CRA foi vista e aprovada pela Assembleia Constituinte, em 21 de Janeiro de 2010 e, na sequência do Acórdão do Tribunal Constitucional n.o 111/2010, de 30 de Janeiro, em 03 de Fevereiro de 2010.

3. A actual Constituição, representa o culminar do processo de transição, iniciado em 1991, com a aprovação pela Assembleia do Povo da Lei n.o 12/91, de 6 de Maio, que consagrou «a democracia multipartidária, as garantias dos direitos e liberdades fundamentais dos cidadãos e o sistema económico de mercado», mudanças aprofundadas pela Lei de Revisão Constitucional n.o 23/92, de 16 de Setembro.

4. Trata-se do Decreto-Lei $n . .91 / 07$, de 02 de Janeiro do Conselho de Ministros, que aprova o Estatuto Especial para a Província de Cabinda (EEC) e a Resolução n.o 27-B/06, de 16 de Agosto da Assembleia Nacional, que estabelece o Memorando de entendimento para a paz e reconciliação na Província de Cabinda (MEPRC).

5. Os actores operacionais do poder, não significa que correspondam aos actores formais. Eles poderão ser formais não visíveis e informais. A este propósito, Adriano Moreira (1964) conclui que «não ajuda muito saber quem é que aparentemente tem o poder de decidir, interessa saber quem é que realmente decide» (Adriano Moreira, apud ROMANA 2005: 22).

6. O FCD, foi criado em 2004, no âmbito de uma reunião inter-cabindesa, realizada entre 23 e 29 de Agosto, em Emmaus (Helvoirt, Reino da Holanda). Entre outras decisões tomadas e efectivadas, assumem particular relevância, a de fundir os dois maiores, e mais antigos movimentos políticos e militares de Cabinda: a FLEC/Renovada de António Bento Bembe e a FLEC/FAC de Henriques Tiago Nzita, num só movimento político-militar, que retoma a histórica designação de 02 de Agosto de 1963 (Brazzaville) - FLEC (Frente de Libertação do Enclave de Cabinda) e a de instituir um novo organismo negocial e que funcione como espaço de concertação política - Fórum Cabindês para o Diálogo (FCD) que congrega elementos da FLEC unificada, outros grupos e tendências políticos, igrejas, associações e entidades civis de Cabinda, para responder ao imperativo da busca pela paz entre o Povo de Cabinda e o Governo de Angola.

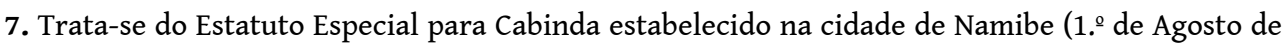
2006), nos termos do Memorando de entendimento para a paz e reconciliação na Província de Cabinda.

8. Como dissemos atrás, o "futuro indesejável» é aquela política ou solução que o Governo considera necessário evitar ou contrariar, por não corresponder aos seus objectivos políticos (RIBEIRO 1998: 148).

9. Reportando-nos aos Movimentos Nacionalistas de Cabinda, Dom Duarte de Bragança (Março e Abril de 2001), afirma que «a sua grande fraqueza é a divisão em duas facções militares e a existência de graves divergências entre os seus políticos, que retira credibilidade internacional ao movimento». Cf. «Cabinda e Timor», Diário de Notícias de 25 de Março de 2001 e Revista Real n.․ 47/48, Abril-Setembro (Lisboa), pp. 12-13.

10. Com a multiplicação em flecha de FLEC's, onde todos reivindicam a sua legitimidade, deu-se o argumento de força ao Governo Angolano para afirmar que «não há um interlocutor válido para negociar a paz em Cabinda», aproveitando as divergências na resistência para as mediatizar largamente, reforçando assim os seus argumentos. 
11. Segundo António da Silva Ribeiro, por um lado, o "futuro desejável», corresponde àquele que na óptica do Governo melhor servirá as finalidades últimas da política, por outro lado, o «futuro aceitável» corresponde àquele que, embora não sendo considerado pelo Governo o melhor, ainda serve aquela finalidade (RIBEIRO 1998: 148).

12. Inspira-se na alínea b) do art. $16 .^{\circ}$ e nos n.os 1 e 2 do art.. $106 . \circ$ do EEC.

13. Tal como deixamos dito atrás, os termos «cabindês/cabindeses, Cabinda ou cabindiano/ cabindianos» são frequentemente usados para designar o(s) cidadão(s) autóctone(s) do território enclave de Cabinda (e por "cabindense ou cabindenses», entende-se os habitantes do território da província de Cabinda em geral (independentemente das suas origens).

14. Quem poderá negar que, para os povos polaco, judeu, irlandês ou eventualmente outro em iguais circunstâncias, o empenhamento no combate nacional tenha surgido de uma imperiosa necessidade?

15. Não admira, pois, que em África os regimes possuam forças militares, forças policiais, palácios e parlamentos, mas demonstrem uma enorme incapacidade em promover o desenvolvimento.

16. Defender o modelo federal para Cabinda é o mesmo que caminhar para propósitos inconcebíveis e inaceitáveis porque impraticáveis e inatingíveis para a instituição de um Estado democrático multinacional em Angola (contrarie a CRA). Não pretendemos uma segunda Nigéria em África - que seria uma possível consequência da opção federal. $O$ instituto de federalismo enquadra-se na atribuição de autonomias alargadas às entidades federadas. Enquanto o Estado unitário assenta na uniformidade, o Estado federal baseia-se, por definição, na aceitação da pluralidade interna. Por maior respeito que o federalismo demonstra para com as especificidades socioculturais que possam localmente existir, não é suficiente para contrariar a longo prazo as dinâmicas nacionalistas claramente separatistas (BEMBE 2014: 211-212).

17. Em certo sentido os fins e as funções do Estado encontram-se indissociavelmente ligados, na justa medida em que as necessidades colectivas que são a razão da existência do Estado, dependem, na sua concretização, das actividades que o Estado exerça para as satisfazer (BEMBE 2014: 218; 2013b: 179).

18. Os homens, individualmente, são incapazes de satisfazerem todas as suas necessidades materiais e espirituais, pelo que o Estado, através do poder político que exerce, se justifica também, para suprir as necessidades cada vez mais alargadas de um cada vez maior número de cidadãos, o que leva o poder político do Estado a cumprir a finalidade do bem-estar económico e social (BEMBE 2014: 218-219; 2013b: 179).

19. Trata-se da Resolução n.. 27-B/06 de 16 de Agosto e do Decreto-Lei n.․ 1/07 de 2 de Janeiro.

20. Inspira-se na abordagem adoptada por António Silva Ribeiro (RIBEIRO 2010: 125).

21. Na Catalunha, o processo secessionista tem-se revelado abertamente desde há muitos anos por uma minoria e, desde Setembro de 2002, por uma maioria.

\section{RESUMOS}

A investigação da qual resultou o presente artigo visou apresentar um novo modelo e processo de partilha do poder no Enclave angolano de Cabinda, que poderá contribuir para conferir um acréscimo de sustentação teórica e de rigor metodológico ao processo instituído pelo Decreto-Lei n.. 1/07, de 02 de Janeiro de Conselho de Ministros, que aprova o «Estatuto Especial para a Província de Cabinda (EEC)», resultado da Resolução no 27-B/06, de 16 de Agosto da Assembleia 
Nacional, que estabelece o Memorando de entendimento para a paz e reconciliação na Província de Cabinda (MEPRC).

Para isso, começou por identificar, entender e explicar as motivações e as causas de convivência menos saudável entre Luanda e Cabinda, o conhecimento da sociedade cabindesa e as possíveis redes de poder nela existentes. Depois, analisou os procedimentos aplicados no modelo do EEC, e em conhecidos modelos de regulação, contenção e gestão de conflitos político-identitários internos. A partir da articulação lógica daqueles conceitos e procedimentos, com recurso à imaginação criativa e a alguns casos paradigmáticos de uma arrumação contemporânea de relações, factos e processos socio-culturais, históricos e políticos, foi concebido um modelo original de partilha do poder no Enclave de Cabinda, sem perder de vista a sua necessária contextualização à luz da realidade angolana.

o desenvolvimento do modelo proposto teve por base o estudo e a análise das estratégias mais comuns e modelos paradigmáticos frequentemente recorridos pelos Estados nos cenários contemporâneos para a prevenção, gestão e resolução pacífica de conflitos internos, secessionistas, político-identitários ou sócio-culturais, desde as federações e arranjos territoriais das populações, os modelos democráticos, da divisão do espaço e do território à partilha de poder e ao pluralismo.

This research aims to bring forth a new approach and process of power-sharing over the Angolan Enclave of Cabinda, which may contribute to add theoretical arguing and methodology systematization to the process institutionalized by the Decree-Law No. 1/07, of January 2nd, of Ministry Council, that adopted the Especial Status of the Cabinda Province (EEC), in result to the Resolution 27-B/06, of August 16th, of National Assembly, establishing the Memorandum of Understanding for Peace and Reconciliation in Cabinda Province (MEPRC).

To reach the above proposal, the research starts by identifying, understanding and explaining the motivations and causes of a less healthy relationship between Luanda and Cabinda, the knowledge of the Cabinda Society and possible networks of power that exist within it. After, the research analysis the processes applied to the model of EEC, based on known models of regulation, containment and management of internal political-identity conflicts. By articulating those concepts and processes, resorting to creative imagination and to some pragmatic cases of contemporary relations arranging, facts and sociocultural processes, historic and political, was designed an original model of power-sharing on the Enclave of Cabinda.

The development of the proposed model is based on the analyses of common strategies and paradigmatic models usually applied by States in contemporary settings to prevent internal conflict and resolutions, secessionists, political-identity or sociocultural, from federations and territorial arrangement of populations, democratic models, of space division and territory to power-sharing and pluralism.

\section{ÍNDICE}

Keywords: Angola post-conflict, The Cabinda issue, Power-sharing, The State of law Building, Consolidation of peace and democratic institutions

Palavras-chave: Angola pós-conflito, A questão de Cabinda, Partilha do poder, A Construção do Estado de direito, Consolidação da paz e das instituições democráticas 


\section{AUTOR}

\section{MIGUEL DOMINGOS BEMBE}

miguelbembe@gmail.com

Professor Auxiliar da Faculdade de Ciência Sociais da Universidade Agostinho Neto (FCS-UAN) e Investigador do Centro de Investigação em Análise de Políticas e Sistemas Eleitorais (CIAPSE/FCSUAN), em Luanda-Angola.Universidade Agostinho Neto (UAN).

É Doutor e Mestre em Ciências Sociais, respectivamente, na especialidade de Ciência Política (13 de Maio de 2014) e Estratégia (31 de Março de 2009) pelo Instituto Superior de Ciências Sociais e Políticas da Universidade de Lisboa, em Portugal. É Assessor Principal no gabinete do Ministro das Relações Exteriores do Governo da República de Angola, Professor Auxiliar no Departamento de Ciência Política da Faculdade de Ciências Sociais (FCS) da Universidade Agostinho Neto (UAN), onde lecciona Análise Política; Geopolítica e Geoestratégia; Políticas de Segurança e Defesa Nacional; Informações e Segurança; Teoria e Prática da Democracia e Investigador do Centro de Investigação em Análise de Políticas e Sistemas Eleitorais (CIAPSE) da FCS - UAN, em Luanda. É autor dos seguintes artigos: "Os vectores da construção da "Nação-angolana" e a função do Estado», in Mulemba - Revista Angolana de Ciências Sociais (Luanda), vol. III, n. ${ }^{\circ}$ 6, Novembro de 2013, pp. 167-183; «Poder local e democracia em Angola. Oportunidades e desafios», in Mulemba Revista Angolana de Ciências Sociais (Luanda), vol. II, n.o 3, Maio de 2012, pp. 35-57; «O Estado e o poder tradicional em Angola», in Mulemba - Revista Angolana de Ciências Sociais,(Luanda), vol. I, n.․ 2, Outubro de 2011, pp. 9-27); e das obras seguintes: Mecanismos de partilha do poder e acomodação das elites. Modelo e processo para o Enclave de Cabinda. Lisboa, Instituto Superior de Ciências Sociais e Políticas, 2014 [«Colecção Estudos políticos e sociais»]; A questão de Cabinda - Uma visão estratégica. Luanda, Edição do Autor, 2013; O terrorismo transnacional. Estratégias para o seu combate. Luanda, Edição do Autor, 2012; O estudo científico da Ciência Política. Abordagens epistemológicas e metodológicas, Luanda, Edições Mulemba; Mangualde, Edições Pedago, 2013, em co-autoria com Paulo Faria e Fernando Muquepe. 